Dysphagia was the main problem for medicines administration $(86.5 \%)$, while other factors such as blinded medicines $(7.7 \%)$ or enteral tube feeding $(5.8 \%)$ were less frequent.

The specialist pharmacist made 135 recommendations and prescription adaptations of which 94 (69.6\%) involved changes on drug administration: crush tablets (42; 44.7\%), change dosage forms (30; $31.9 \%)$, dissolve tablets and oral forms $(11 ; 11.7 \%)$, change of therapeutic agent $(9 ; 9.6 \%)$ and withdrawal of medicine $(2 ; 2.1 \%)$. Acceptance among physicians and nurses of medicines administration guides for all 52 patients was high (98.9\%).

Conclusions Pharmacists play an important role in adapting treatments of patients with dysphagia and feeding disorders, therefore ensuring safe administration of drugs. The implementation of individualised medicines administration guides supports individualised care and is generally well accepted.

No conflict of interest.

\section{CPC-021 ASSESSMENT OF PATIENT KNOWLEDGE IN A REHABILITATION WARD AND CREATION OF A TEACHING AID IN THE TREATMENT OF PAIN}

doi:10.1136/ejhpharm-2013-000276.478

${ }^{1}$ A Camerlynck, 'S Allemon-Dewulf, ${ }^{2} \mathrm{C}$ Haxaire, ${ }^{2} \mathrm{MJ}$ Kins, 'M Delobel. 'Hopital Maritime, Pharmacy, Zuydcoote, France; 'Hopital Maritime, Rehabilitation Ward, Zuydcoote, France

Background The management of pain is one of the priorities of our hospital, which specialises in follow-up and rehabilitation care. A lack of knowledge about the pain and its treatment can limit the patient's adherence to painkillers and lead to side effects or overdose.

Purpose To create a teaching aid on the treatment of pain. It was written with the cooperation of two doctors. A questionnaire was developed to assess patients' knowledge of the painkillers they had been prescribed.

Materials and Methods A list of open questions about painkillers was developed:

- name of their painkiller (International Nonproprietary Name (INN), trade name),

- the dosage, when to take the drugs, the maximum daily dose/time interval between doses,

- the meaning of 'sustained-release drug' and 'orodispersible',

- side effects and how to avoid them, contraindications, possible drug interactions,

- how to use painkillers depending on the intensity of the pain,

- withdrawal from tramadol and codeine,

- alternatives to pain treatment.

Eleven patients were interviewed.

Results Overall, patients knew the trade name of their painkiller $(72 \%)$ but only $9 \%$ of patients knew the INN. $72 \%$ could quote the exact dose. $54 \%$ of patients knew the maximum daily dose and the period of time between doses. Nearly all patients didn't know the meaning of 'sustained-release drug' and 'orodispersible' (81\% and $91 \%$ ). The use of painkillers depending on pain intensity was well reported in 5 cases (45\%). Side effects and how to avoid them, contraindications and possible drug interactions, were not well known subjects. Finally, $27 \%$ of patients quoted alternatives to pain treatment.

Conclusions This assessment enabled us to target patients' lack of knowledge about painkillers and to develop a booklet providing all the information required. This leaflet has been checked by doctors. Patients who were part of this study gave feedback on the booklet, which will now be distributed to patients.

No conflict of interest.

\section{CPC-022 ASSESSMENT OF THE RELEVANCE OF FLUOROQUINOLONE PRESCRIPTIONS IN THE INTERNAL MEDICINE DEPARTMENT AND IMPACT ON ANTIBIOTIC STEWARDSHIP}

doi:10.1136/ejhpharm-2013-000276.479

PA Jolivot, A Gonthier, E Camps, B Bonan. FOCH Hospital, Pharmacy, Suresnes, France

Background In our hospital, the consumption of fluoroquinolone (FQ) antibiotics has increased since 2004. Moreover, the development of quinolone-resistant strains of Escherichia coli and their spread have become a worrying issue. The FQs available in our hospital are norfloxacin (Nor), ofloxacin (Oflo), ciprofloxacin (Cip), levofloxacin (Levo). Cip and Levo access are restricted by the hospital formulary. The Antimicrobial MultiDisciplinary Team (AMDT), composed of the pharmacy resident and a clinical microbiologist, reviews all prescriptions daily before dispensing.

Purpose To assess the relevance of FO prescriptions in the department of Internal Medicine and then to initiate a thoughtful consideration of non-restricted fluoroquinolones.

Materials and Methods Over a six-month period, all cases of FO prescriptions for acute infections were analysed by both a pharmacy resident and a bacteriologist. Appropriateness of prescriptions was determined by using a therapeutic suitability index, which investigated relevance of $\mathrm{FO}$ and drug prescribed, dosage adjustments, duration of treatment and route of administration.

Results Forty-three prescriptions were assessed. Ofloxacin was the most prescribed FQ representing $72 \%$ of the prescriptions, followed by ciprofloxacin (16\%), levofloxacin (7\%) and norfloxacin (7\%). Fewer than $33 \%$ of prescriptions adhered to guidelines for all items. Another antibacterial family should have been prescribed in $11 \%$ of cases ( 3 Oflo and 2 Nor). The drug prescribed was judged debatable in $25 \%$ of cases ( 9 Oflo and 2 Cip). Dosage was not adapted to renal function in 4 prescriptions. Route of administration was justified for all prescriptions.

Conclusions These results were presented to the antibiotic control committee. Because of the overuse and misuse of ofloxacin, it has been decided to restrict its access, which will lead to improve quality of fluoroquinolone usage.

No conflict of interest.

\section{CPC-023 ASSESSMENT OF THE WHOLE INTERCEPTIVE AND POST-FERTILISATION EFFECTS OF POSTCOITAL LEVONORGESTREL}

doi:10.1136/ejhpharm-2013-000276.480

EJ Alegre-del Rey, S Fénix-Caballero, JF López-Vallejo, MJ Ladrón de Guevara, MA Blanco-Castaño, E Ríos-Sánchez, JM Borrero-Rubio. ${ }^{1}$ Hospital Universitario Puerto Real, Pharmacy, Puerto Real (Cádiz), Spain

Background Taking into account the whole interceptive effect, anovulatory potency and timing of administration, it's possible to calculate what proportion of interceptive (contraceptive \pm contragestive) effects of levonorgestrel take place as anovulatory action. However, we don't know the actual interceptive effect, because clinical trials didn't use a placebo group.

Purpose To discover the interceptive effect after a single dose of levonorgestrel, and then calculating the proportion of its anovulatory and possible post-fertilisation effects.

Materials and Methods A recent systematic review pulled data from 6,794 women. Levonorgestrel administered the fifth day after intercourse showed a probability of pregnancy of $5.2 \%$, slightly lower than the 6-8\% calculated by an estimation method. Using this cohort as a control group, we estimated the interceptive effect 